\title{
BRIEF COMMUNICATION Long-term effects of smoking cessation support in primary care: results of a two-year longitudinal study in Brazil
}

\author{
Efeitos a longo prazo do suporte na cessação do tabagismo na atenção \\ primária: resultados de um estudo longitudinal de dois anos no Brasil \\ Nádia Cristina Pinheiro Rodrigues, , Mônica Kramer de Noronha Andrade1,3, Gisele 0'Dwyer', \\ Regina Paiva Daumas', Regina Dias Neves', André Pereira Neto', Maria Clara da Silva Dutra', \\ Alyssa Gerardi ${ }^{4}$, Valéria Teresa Saraiva Lino ${ }^{1}$
}

\begin{abstract}
Objective: The objective of this study was to evaluate the long-term effects of a Brazilian smoking cessation support program and the factors that are associated with its success. Methods: A longitudinal study was conducted from 2012 to 2014 with 84 patients enrolled in smoking cessation support groups in a Primary Care Center from a poor community in Rio de Janeiro (Brazil). Support was provided according to Brazilian Tobacco Control Program and consisted of cognitive behavioral therapy in addition to nicotine replacement therapy. Logistic regression and the Cox proportional hazard models were used in the analysis. Results: There was an increase of $34 \%, 48 \%$ and $97 \%$ in the chances of patients stop smoking for at least six months, 12 months and 24 months, respectively, for each new session that the patient participated. Patients that attended three or more meetings had a 79\% lower risk of returning to smoking than those who went to less than three meetings. Conclusions: Although not all patients who were enrolled in the program could be contacted for the study, our results indicate that about $40 \%$ of patients are able to stay smoke-free for at least three months due to the smoking cessation program, but less than $20 \%$ are able to remain smoke-free for two years. Initiatives to improve adherence to cognitive behavioral therapy meetings according to the specificity of the population may increase the effectiveness of the program.
\end{abstract}

\section{RESUMO}

Objetivo: $\mathrm{O}$ objetivo deste estudo foi avaliar o efeito a longo prazo de um programa de suporte à cessação do tabagismo e os fatores associados ao sucesso do tratamento. Métodos: Conduzimos um estudo longitudinal de 2012 a 2014, no qual 84 pacientes foram incluídos em grupos de suporte à cessação do tabagismo em um Centro de Atenção Primária de uma comunidade de baixo poder aquisitivo do Rio de Janeiro (Brasil). O tratamento seguiu as orientações do Programa Nacional de Controle do Tabagismo do Brasil, consistindo em terapia cognitivo-comportamental, adicionado à reposição de nicotina. Modelos de riscos proporcionais de Cox e de regressão logística foram usados na análise. Resultados: Houve um aumento de

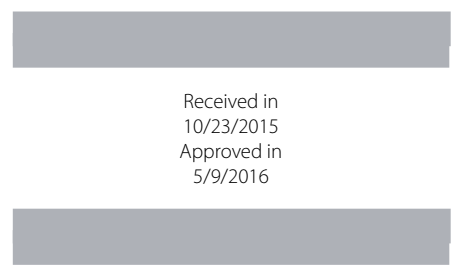

1 Oswaldo Cruz Foundation, National School of Public Health Sergio Arouca, Rio de Janeiro, RJ, Brazil. 2 Rio de Janeiro State University (UERJ), School of Medical Sciences, Rio de Janeiro, RJ, Brazil. 3 Vital Brazil Institute, Centre for Studies and Research on Ageing, Rio de Janeiro, RJ, Brazil. 4 Georgetown University, Washington, DC, USA.

Address for correspondence: Nádia Cristina Pinheiro Rodrigues

Oswaldo Cruz Foundation

Telephone: (+55 21) 2598-2848

DOI: 10.1590/0047-2085000000120 


\section{Palavras-chave}

Tabagismo, tabaco, nicotina, Programa

Nacional de Controle do

Tabagismo, efeito a longo

prazo.
$34 \%$, 48\% e 97\% na chance dos pacientes pararem de fumar por pelo menos seis meses, 12 meses e 24 meses, respectivamente, a cada nova sessão que o paciente participou. Os pacientes que compareceram a três ou mais encontros tiveram risco $79 \%$ menor de voltar a fumar do que aqueles que foram a menos de três encontros. Conclusões: Apesar de não ter sido possível contatar todos os pacientes do programa para participar do estudo, nossos resultados indicam que cerca de $40 \%$ dos participantes conseguiram parar de fumar por pelo menos três meses, porém menos de 20\% foram capazes de parar por dois anos. Iniciativas para melhorar a adesão aos encontros de terapia cognitivo-comportamental, respeitando as especificidades de cada população, podem ser úteis para aumentar a efetividade do programa.

\section{INTRODUCTION}

The tobacco epidemic is a global public health problem that surpasses country borders. Smoking causes around six million deaths worldwide per year'. Although smoking was considered an elegant lifestyle in the past, nowadays it is known that it is a dangerous habit involving physical and psychological dependence ${ }^{1,2}$.

The per capita consumption of cigarettes in Brazil fell around 33\% between 1989 and 20043, as well as the prevalence of smokers in Brazil, which fell 46\% from 1989 to $2010^{4}$. Several initiatives have contributed to the decrease: increases in cigarette price, smoke-free air laws, marketing restrictions, health warnings, mass media campaigns, and cessation treatment programs ${ }^{4}$. However, the success rate of tobacco cessation treatment is quite low in Brazil ${ }^{5}$.

A number of articles report the success of the smoking cessation program, but few studies have evaluated the long-term effectiveness of smoking cessation support under the Tobacco Control Program ${ }^{6-8}$. Therefore, this study evaluated the long-term effects of the Brazilian smoking cessation program and the factors associated with the success of the treatment.

\section{METHODS}

This is a cohort study of patients undergoing the smoking cessation program according to Brazilian Tobacco Control Program from January 1st, 2012 to December 31, 2014 at the National School of Public Health (ENSP) of the Oswaldo Cruz Foundation (Fiocruz) in Rio de Janeiro, Brazil.

Since 1967, ENSP is the reference for primary health care of the Manguinhos community (city of Rio de Janeiro). This is a low-income and low-educational level community with approximately 20,000 inhabitants and a household density of 2.8 persons per dwelling.

The smoking cessation program is aimed at smokers who want to quit smoking. It has been held in ENSP since 2012, and patients enrolled in the program are invited to participate in seven meetings. After an anamnesis session, pa- tients participate in weekly meetings of cognitive behavioral therapy for four weeks and then have monthly monitoring sessions for two months. The patient starts using nicotine replacement at the first session (anamnesis), which is freely available to program participants.

Data were collected from medical records and a telephone survey was conducted to the patients enrolled in smoking cessation program to estimate its effectiveness in smoking cessation, specifically the value of cognitive behavioral therapy in addition to nicotine replacement therapy (Figure 1). The Brazilian Health Ministry's protocol for nicotine patch use was utilized in the nicotine replacement therapy for all patients. According to the protocol, people who smoke less than 20 cigarettes/day and those who smoke more than 20 cigarettes/day are treated for 8 weeks and 20 weeks, respectively?

The eligibility criteria to enter in the study were: 1) participation in the smoking cessation program in the 2012-2014 period; 2) provision of a telephone number to be contacted; and 3) answered at least one of the three telephone calls of the interviewer. Among the 245 patients who participated in the smoking cessation program from 2012 to 2014, 84 met the eligibility criteria and were included in the study.

\section{Explanatory variables}

Sex, age, meetings (frequency of meetings attended throughout the treatment), low education level (lower than elementary school), low income (lower than $\$ 445.00$ ), high alcohol consumption (score greater than one in CAGE scale) ${ }^{9}$ and nicotine dependence level (score of Fagerstrom scale) ${ }^{10}$.

\section{Outcomes}

Smoking cessation (at least three months, at least six months, at least one year and at least two years) and failure (numeric variable of the time until a patient returned to smoking within two years of starting treatment). Failure was also evaluated as a categorical variable (relapsed in the first three months, relapsed between three and six months, relapsed between six and twelve months, and relapsed between twelve and 24 months). 


\section{Statistical analysis}

Frequency of categorical variables, summary of numerical variables (mean, standard deviation and quartiles), 95\% confidence interval $(95 \% \mathrm{Cl})$ and statistical tests $(a=0.05)$ were used to describe and compare the observed characteristics of study participants.

The multiple logistic regression model, adjusted by age, sex and income, was used to estimate the chance of quitting smoking according to the frequency of meetings attended. The Cox proportional hazard model, adjusted by age, sex and income, was used to estimate the risk of returning to smoking according to the frequency of meetings attended.

\section{Ethics statement}

The study followed the principles set forth in the Declaration of Helsinki and was approved by the Institutional Review Board of the facility where the study was carried out through the Ethics Committee of Escola Nacional de Saúde Pública Sergio Arouca, Fundação Oswaldo Cruz (ENSP/Fiocruz) (protocol 624,550).

\section{RESULTS}

Among the 245 patients who entered in the smoking cessation program from 2012 to 2014, 84 participants were included in the study, while 161 could not be contacted to participate of the study (non-participants). Figure 1 shows the differences between the two groups: participants and non-participants. There was no statistical difference in age, sex, low education level, high alcohol consumption, dependence level and the interval between the beginning of the treatment and the interview. However, there was a significant difference between the frequency of meetings attended throughout the treatment ( $p$-value $<0.01$ ) and the frequency of low-income patients ( $p$-value $<0.03$ ). While the median number of meetings attended by the participants was five, it was only three for non-participants. As well, the percentage of low-income patients was 58.5\% among participants and $73.1 \%$ in non-participants.

Among the 84 study participants: 50 (59.5\%) smoked within three months of starting treatment and 34 (40.5\%), 30 (35.7\%), 26 (31.0\%), 16 (19.0\%) were smoke-free at least three months, six months, 12 months and 24 months after, respectively (Figure 2).

Among the 68 (81.0\%) participants who returned to smoking over the two-year study period, $93.6 \%$ would like to try to stop smoking again and most of them (60.9\%) would like to return to the smoking cessation program.

For all the participants the median score of Fagerstrom scale was the same: seven, indicating high nicotine dependence. However, among the failures cases, there was a significant reduction in the Fagerstrom score after they underwent the treatment (median difference between the first and last score $=1 ;$ p-value $<0.001$; paired Wilcox test).

For each meeting in which the patient participated, there was an increase of $41 \%, 38 \%$ and $59 \%$ in the chance of remain smoke-free for at least three months, six months and 12 months, respectively. The effect of the frequency of the meetings was greater than twice for those who reached two years in smoking abstinence (data adjusted by age, sex and income) (Table 1).

The log-rank test demonstrated that the probability of returning to smoking was significantly different based on income status ( $p$-value $<0.02$ ) and the frequency of meetings attended ( $p$-value $<0.001$ ), but there was no statistical difference in the probability of returning to smoking according to sex and age.

The Cox proportional hazard model, adjusted by sex, age and income, showed that patients who attended three or more meetings had a $79 \%$ lower risk of returning to smoking than those who went to less than three meetings ( $p$-value $<$ 0.01) (Table 1).

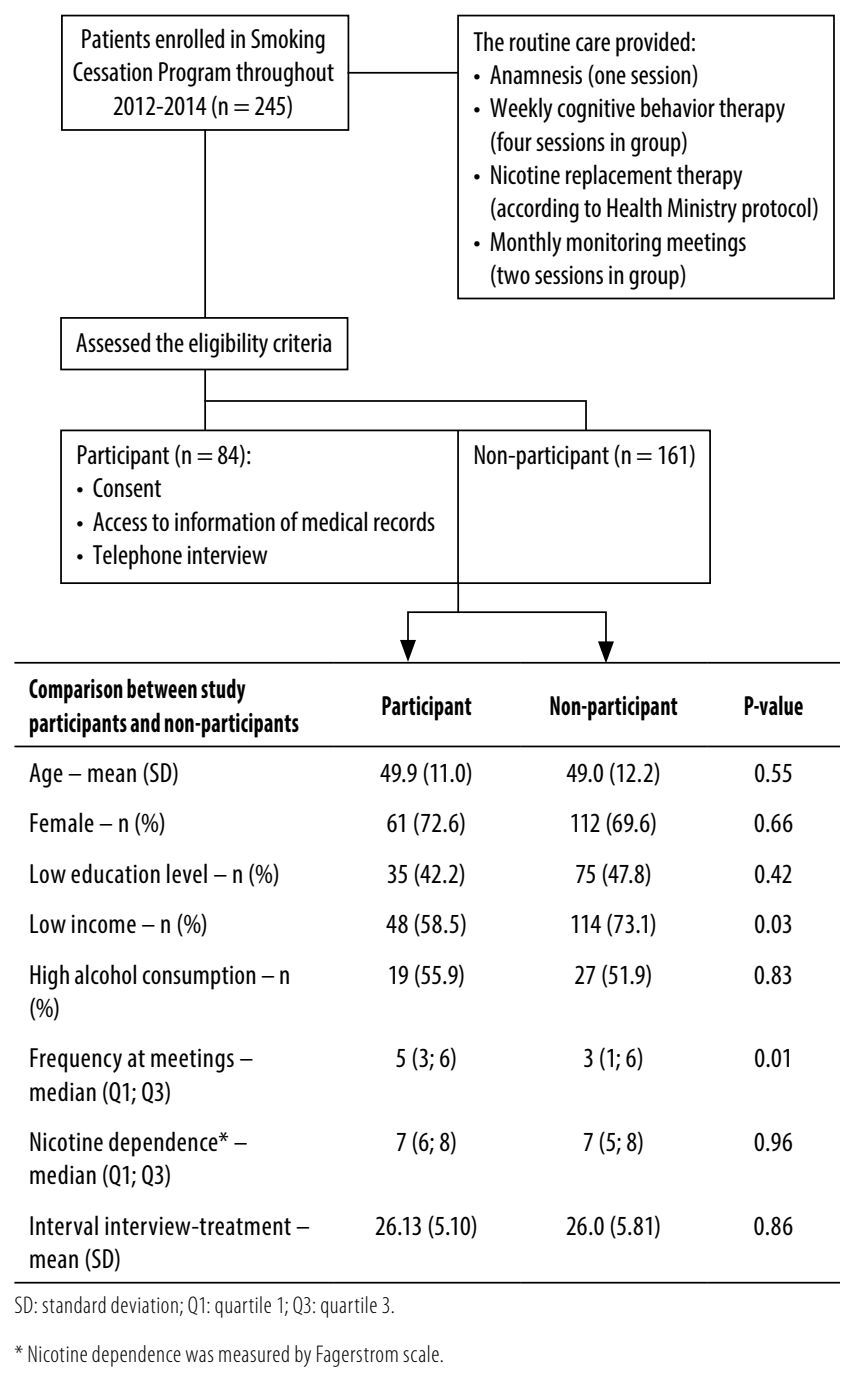

Figure 1. Research steps. 


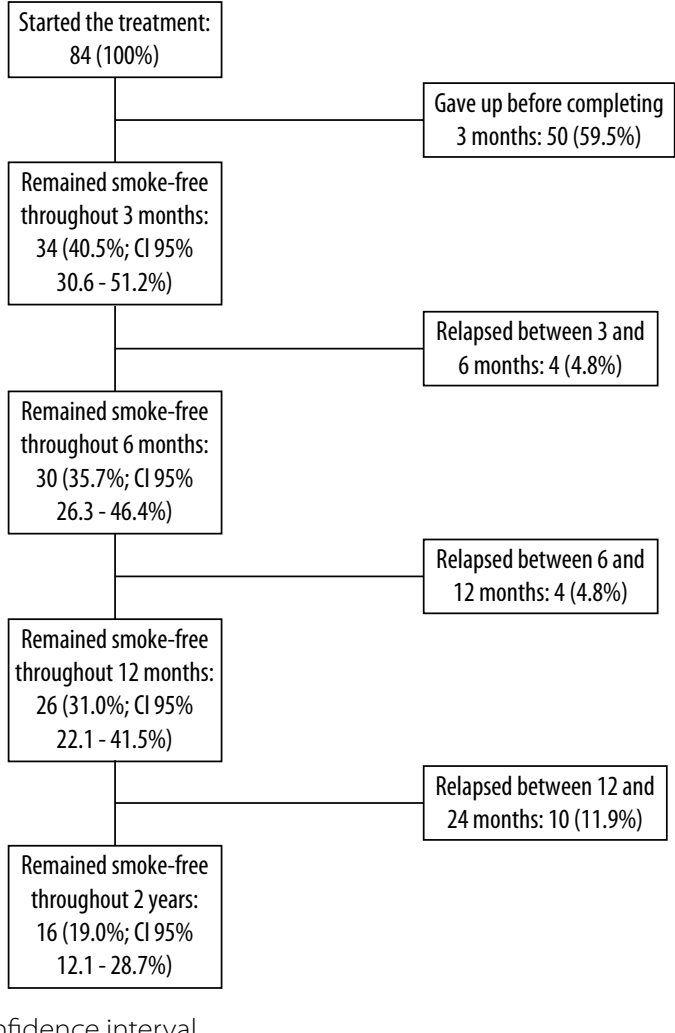

Cl: confidence interval.

Figure 2. The amount of success and failure of the study participants over time.

Table 1. The effect of greater participation in the cognitive behavior therapy meetings to treatment success or failure

\begin{tabular}{lccc}
\hline \multicolumn{4}{c}{ Effect of main factors on the risk of failure } \\
\hline Factors: & $\mathrm{RR}^{\epsilon}$ & $\mathrm{Cl} 95 \%$ & $\mathrm{p}$-value \\
Meetings (ref: $<3$ ) & 0.21 & $0.08-0.54$ & 0.001 \\
Age & 0.99 & $0.96-1.03$ & 0.60 \\
Sex (ref: fem) & 0.49 & $0.18-1.33$ & 0.16 \\
Income in dollars & 1.12 & $0.50-2.52$ & 0.79 \\
(ref: $<$ 445.00) & \multicolumn{3}{l}{} \\
\hline \multicolumn{4}{l}{ Effect of attendance at meetings to quit smoking } \\
\hline Outcomes: & $0 \mathrm{R}^{*}$ & Cl 95\% & $\mathrm{p}$-value \\
at least for 3 months & 1.41 & $1.09-1.83$ & 0.01 \\
at least for 6 months & 1.38 & $1.06-1.79$ & 0.01 \\
at least for 12 months & 1.59 & $1.16-2.20$ & 0.001 \\
at least for 24 months & 2.14 & $1.19-3.88$ & 0.001 \\
\hline
\end{tabular}

Cl: confidence interval; OR: odds ratio; RR: relative risk; fem: female; ref: reference.

${ }^{\mathrm{E} C}$ Cox proportional hazard model - outcome: return to smoke; independent variables: meetings, age, sex and income. * Each logistic regression model was adjusted by age, sex and income.

\section{DISCUSSION}

Several studies point that there was a reduction of cigarette use in recent years after different government initiatives to decrease the prevalence of smokers ${ }^{11-13}$. According to a systematic review, group therapy is more effective than self-help to quit smoking, and nicotine replacement therapy doubles the chance of quitting ${ }^{14}$.

Our findings show that less than $20 \%$ of patients who enter in the smoking cessation program are able to remain smoke-free for two years, and about 30\% remain smokefree for one year. We also found a constant reduction in the proportion of patients who were smoke-free over time. Terry et al., 2011, found that 32\% of the participants in an American telephone-based tobacco cessation program (2004-2006) stopped smoking for 12 months, while only $18 \%$ of the non-participants were able to quit in the same period ${ }^{15}$. In a German follow-up study (2002-2004), patients who were submitted to an intervention to quit smoking were medicated and received lifestyle guidance. Results showed that smoking prevalence decreased from $21.7 \%$ to $16.6 \%$ after one year and to $15.3 \%$ after two years ${ }^{16}$.

Our results highlight the importance of complete participation in all cognitive behavior therapy meetings for the success of the treatment. The more meetings patients attended, the greater the chance of remaining smoke-free for a longer period of time. A Brazilian study (2007-2008) found that about $24 \%$ of patients give up tobacco treatment after the first cognitive behavioral therapy session ${ }^{17}$.

In poor communities of Rio de Janeiro, it is common that the people do not have a fixed telephone number but rather a cell phone. In addition, both patients in the program and those on the waiting list often change their telephone number and place of residence throughout the year. This situation made it difficult to contact patients after they entered in the smoking cessation program, and as a result, only a third of these patients could be contacted for the interview. As well, the high demand of smokers seeking treatment reduced the possibility for those who have relapsed to enter into treatment again. This is because relapsed patients return to the waiting list if they seek treatment again. Only one patient was re-enrolled in the tobacco treatment program over the two-year study period.

A further limitation in this study was the lack of referral to additional exams to evaluate the nicotine dependence of enrolled patients such as carbon monoxide levels.

Based on the design structure, the study population was characterized by higher income than non-participants and had greater regularity in meeting attendance. Since one of the eligibility criterion required that the participant had a phone to be contacted, the higher income of participants is justified. The success percentage is also probably overestimated since the study selected smokers who attended more frequently in cognitive behavior therapy sessions.

Another limitation is that data were collect by interview, so the outcome occurrence was established from the patient report and not from direct observation. 


\section{CONCLUSIONS}

Public health initiatives influence changes in tobacco use. Although several smokers give up being smoke-free before they complete the program, a portion of smokers can benefit. Few studies have evaluated long-term effects of the Brazilian government's program to control tobacco use, so it is difficult to evaluate the consistency of our results. Initiatives to improve adherence to cognitive behavioral therapy meetings according to the specificity of the population may increase the effectiveness of the program.

\section{INDIVIDUAL CONTRIBUTIONS}

Nádia Cristina Pinheiro Rodrigues - Had substantially contributed to conception and design or analysis and interpretation of data; had substantially contributed to drafting the article or revising it critically for important intellectual content; and had given the final approval of the version to be published.

All the authors had substantially contributed to drafting the article or revising it critically for important intellectual content; and had given the final approval of the version to be published.

\section{CONFLICTS OF INTEREST}

No conflict of interest.

\section{ACKNOWLEDGMENTS}

The authors thank Fabiana Pessoa, Maria Antônia Silva Costa, Wanessa Araujo Pereira and João Carlos de Souza for their assistance with data collection.

\section{REFERENCES}

1. WHO. 2012 global progress report on implementation of the WHO Framework Convention on Tobacco Control Switzerland. 2012. [cited 2014 Aug. 28, 2014]. Available from: <http:// www.who.int/fctc/reporting/2012_global_progress_report_en.pdf $>$.

2. Rodrigues NC, Neves RD, Mendes DS, Mendes (P, Martins IH, Reis IN, et al. Profile of Brazilian smokers in the National Program for Tobacco Control. Rev Bras Psiquiatr. 2015;37(2):150-4.

3. INCA CNI. [Smoking - INCA] 2014 [cited Aug. 26, 2014]. Available from: <http://www. inca.gov.br>.

4. Levy D, de Almeida LM, Szklo A.The Brazil SimSmoke policy simulation model: the effect of strong tobacco control policies on smoking prevalence and smoking-attributable deaths in a middle income nation. PLOS Med. 2012;9(11):e1001336.

5. 2008 PHS Guideline Update Panel, Liaisons, and Staff. Treating tobacco use and dependence: 2008 update U.S. Public Health Service Clinical Practice Guideline executive summary. Respir Care. 2008;53(9):1217-22.

6. IUHPE. Bloomberg Global Initiative to Reduce Tobacco Use: the International Union for Health Promotion and Education partners for the establishment of a global clearinghouse for effective anti-tobacco advertising. Promot Educ. 2006;13(4):248.

7. Roeseler A, Burns D. The quarter that changed the world. Tob Control. 2010;19(Suppl 1): i3-15.

8. Waters EA, McQueen A, Caburnay CA, Boyum S, Sanders Thompson VL, Kaphingst KA, et al. Perceptions of the US National Tobacco Quitline Among Adolescents and Adults: A Qualitative Study, 2012-2013. Prev Chronic Dis. 2015;12:E131.

9. Mayfield D, McLeod G, Hall P. The CAGE questionnaire: validation of a new alcoholism screening instrument. Am J Psychiatry. 1974;131(10):1121-3.

10. Heatherton TF, Kozlowski LT, Frecker RC, Fagerström KO. The Fagerström Test for Nicotine Dependence: a revision of the Fagerström Tolerance Questionnaire. Br J Addict. 1991;86(9):1119-27.

11. Danaher BG, Severson HH, Zhu SH, Andrews JA, Cummins SE, Lichtenstein E, et al. Randomized controlled trial of the combined effects of web and quitline interventions for smokeless tobacco cessation. Internet Interv. 2015;2(2):143-51.

12. Siegel M. The effectiveness of state-level tobacco control interventions: a review of program implementation and behavioral outcomes. Annu Rev Public Health. 2002;23:45-71.

13. Simpson SA, Nonnemaker JM. New York tobacco control program cessation assistance: costs, benefits, and effectiveness. Int J Environ Res Public Health. 2013;10(3):1037-47.

14. Lancaster T, Stead L, Silagy C, Sowden A. Effectiveness of interventions to help people stop smoking: findings from the Cochrane Library. BMJ. 2000;321(7257):355-8.

15. Terry PE, Seaverson EL, Staufacker MJ, Tanaka A. The effectiveness of a telephone-based tobacco cessation program offered as part of a worksite health promotion program. Popul Health Manag. 2011;14(3):117-25.

16. Muckelbauer R, Englert H, Rieckmann N, Chen CM, Wegscheider K, Völler H, et al. Longterm effect of a low-intensity smoking intervention embedded in an adherence program for patients with hypercholesterolemia: Randomized controlled trial. Prev Med. 2015;77:155-61.

17. Meier DAP, Vannuchi MTO, Secco IAO. [Withdrawal of treatment for smoking in a program of a municipality of northern Parana]. Revista Espaço para a Saúde [Internet]. 2011;13(1):35-44. Available from: <http://www.uel.br/revistas/uel/index.php/espacoparasaude/article/view/10020>. 